\title{
Discursos, saberes e poder: estudo de escritas de professores e especialistas nas revistas educacionais portuguesas (1880- 1900) 1
}

\author{
Maria Cristina Soares de Gouvêa \\ Universidade Federal de Minas Gerais, Brasil
}

\begin{abstract}
Resumo
O texto analisa os discursos sobre o aluno português produzidos por professores e especialistas, presentes nas revistas de educação e ensino do último quartel do século XIX. Tem-se em vista apreender a singularidade das produções discursivas, definidas pela identidade profissional dos autores. Observa-se que os especialistas fazem circular saberes dotados de maior legitimidade social, identificados com o cientificismo característico do período. Por outro lado, os professores, em suas escritas, expressam um saber técnico, fruto do aprendizado das práticas 'escriturísticas' relacionadas ao ofício docente. Define-se um peso social diferenciado, fruto da legitimidade dos autores e dos espaços de circulação discursiva, que informaram historicamente relações de saber/poder.
\end{abstract}

Palavras-chave

Professores; Especialistas; Discursos; Revistas de educação

A recente produção internacional do campo da história da educação, ao contemplar o estudo do século XIX, tem revelado a fertilidade da investigação acerca de tal período, na compreensão dos processos de ordenamento da instituição escolar. Configurou-se a circulação de discursos e práticas de democratização do acesso à instituição, substantivados em 
políticas públicas de escolarização conduzidos por distintos Estados nações. Em que pesem as inequívocas especificidades nacionais e regionais, a grosso modo delineia-se um quadro de difusão da educação elementar e de produção de dispositivos para sua implementação.

Para tal, constituíram-se estratégias pedagógicas definidas pela produção, circulação e apropriação de saberes identificados com a contemporaneidade, visando conferir uniformidade às práticas escolares, fundadas em critérios científicos. Estratégias características do período foram a criação e ampliação das Escolas Normais, a circulação de revistas de educação e ensino, a realização de congressos pedagógicos, concebidos como eventos monumentalizadores da educação.

No que se refere às estratégias jurídicas, as leis de obrigatoriedade escolar implementadas nos distintos países ocidentais, principalmente a partir de 1860, instituíram dispositivos que estabeleciam a escola como espaço da infância (ao definir uma identidade do aluno fundada no seu pertencimento geracional - crianças de 7/8 a 12/14 anos), responsabilidade do Estado (precisando o alcance da oferta da escola pública) e obrigação das famílias (punindo os pais 'faltosos').

Tal recorte era significado nos diferentes quadros nacionais em função da sua história e contexto, demandando do historiador da educação o estudo da singularidade de cada processo. Portugal constitui um interessante locus de investigação, tendo em conta, por um lado, a relativa uniformidade do seu sistema de ensino, a inserção do país nos embates em torno da formulação e implementação de políticas educacionais nacionais no espaço centro europeu e, por outro lado, a afirmação ao longo do período de um "atraso histórico" na efetivação da escola elementar, considerando o quadro continental.

No caso da educação portuguesa, no estudo da larga produção sobre o período ${ }^{2}$, verifica-se a tensão no cumprimento das leis de obrigatoriedade escolar. Em que pese a imprecisão dos dados estatísticos (cf. Candeias, 2004), observa-se que a escola não se constituiu como espaço privilegiado de formação para o grosso da população. Os elevados índices de analfabetismo, a provisoriedade e insuficiência na oferta de escolas indicam um quadro de precariedade característico.

Ao final dos oitocentos, os embates sobre a oferta da escola à população situavam-se em torno de alguns pólos, destacando-se: 
centralização $x$ descentralização do sistema público de ensino; educação primária $x$ secundária, educação pública $x$ particular, co-educação $x$ separação da população escolar por gênero. No dizer de Fernandes (1998: 56):

sob o ponto de vista macroscópico a instrução pública move-se durante o século XIX no interior de um currículo amplo de reestruturações. A contradição entre o ensino clássico e o moderno, o liberal e o ensino prático, entre a centralização e a descentralização atravessa toda a centúria dos oitocentos, inspirando de modo diverso as várias reformas enunciadas em graus diferentes de ensino.

$\mathrm{Na}$ verdade, verifica-se que Portugal, nas duas últimas décadas do século XIX, não conseguiu estender a escola elementar à maioria da população, tendo concentrado esforços na ordenação e funcionamento da escola secundária. Observa-se um privilégio deste nível do ensino, expresso na desigualdade da distribuição de verbas públicas para a educação ${ }^{3}$, nas reformas educacionais implementadas, centradas em tal segmento, bem como no enfoque privilegiado do tema na produção discursiva dos distintos periódicos educacionais. A formação cultural das elites constituía elemento fulcral na constituição de um país moderno, para a qual a estruturação da educação secundária era estratégica. Tal perspectiva é explícita no discurso da Revista de Educação e Ensino (1896: 56):

a educação das classes que devem ser justificadamente dirigentes é uma necessidade [...] a boa direção do povo depende essencialmente dos méritos das classes chamadas a influir nas idéias, a ministrar o ensino, a fazer progredir a ciência, a administrar o Estado.

É no interior deste cenário que tomo como objeto a circulação de discursos e saberes no campo educacional, contemplando três eixos de análise: os autores (professores e especialistas), os espaços de difusão (revistas de educação e ensino) e os tópicos das produções discursivas (com foco nos escritos sobre o aluno).

Tem-se em vista apreender a difusão de saberes sobre o aluno, que era projetado nos discursos educacionais como centro da ordenação pedagógica. Nóvoa (1988: 27) indica a necessidade de ampliação de estudos voltados para o tema na produção portuguesa da história da educação afirmando que "o ator principal da educação e do ensino é obviamente a criança. Paradoxalmente os trabalhos de investigação histórica sobre os alunos não são muito abundantes"4. 
Especialmente no período analisado, com a implementação das leis de obrigatoriedade escolar que destacavam, no interior da população, um extrato geracional ao qual caberia a realização do ofício do aluno, foram difundidos saberes voltados para a otimização de seu desempenho na sala de aula. Afirmava-se a centralidade do aluno na conformação de uma cultura escolar identificada com a contemporaneidade, aluno cuja identidade era definida por seu pertencimento geracional.

$\mathrm{Na}$ ordenação do trabalho pedagógico, configurou-se paulatinamente a homogeneização etária do corpo discente. Os modelos confrontavam-se, na educação secundária, na oposição entre a ordenação por disciplina x classe e, no da educação primária, no delineamento progressivo do modelo de escola graduada, ambas caracterizadas pelo agrupamento de alunos da mesma faixa etária.

Tenho como intento conferir visibilidade às polêmicas levadas a efeito em tal contexto, contemplando a polifonia de discursos sobre este sujeito social, tendo como fonte um dos principais veículos de difusão da ciência pedagógica: as revistas de educação e ensino. Cabe destacar que não é o aluno concreto que ocupava os bancos escolares que busco investigar, mas as produções discursivas que informaram a construção histórica do protagonismo deste ator na cena escolar.

No trabalho de interpretação das fontes, tomo como referência a perspectiva da história intelectual (Falcon, 1997) que, no diálogo com a História Cultural e o referencial foucaultiano, busca analisar a produção científica contemplando sua historicidade no interior de relações de poder que informam sua legitimidade. Como afirma Quentin Skiner (apud Falcon, 2003: 235),

as idéias não se esgotam uma vez (re)conhecido o seu significado; é necessário saber quem os maneja e com quais objetivos, o que só é possível através do (re)conhecimento dos vocabulários políticos e sociais da respectiva época ou período histórico, a fim de que seja possível situar os " textos" no seu campo específico de ação ou de atividade intelectual.

Tendo em vista que a própria definição da ciência constitui uma produção histórica, lança-se o olhar sobre a diversidade de saberes em circulação em diferentes momentos, conferindo visibilidade aos conhecimentos produzidos por autores e em espaços de circulação não circunscritos ao domínio científico. 
Porém, é fundamental considerar, como indica Foucault (1997), que os discursos têm um peso social diferenciado, fruto do lugar dos autores e dos espaços de circulação do conhecimento. É com esta perspectiva que busco contemplar a autoria/espaços de difusão dos saberes sobre o aluno, considerando que a legitimidade dos diferentes textos eram sustentadas em relações de saber/poder. Por outro, busco incorporar as contribuições de Chartier (1991) que, ao trabalhar com as representações sociais, volta-se para a investigação acerca dos seus mecanismos de produção, circulação e apropriação, historicamente definidos. Confrontam-se, para o autor, representações diversas, o que qualifica como "lutas de representações", estabelecidas na disputa entre diferentes grupos sociais. Para Chartier (idem, ib.: 183):

a construção das identidades sociais é resultado sempre de uma relação de força entre as representações impostas pelos que detêm o poder de classificar e de nomear e a definição, de aceitação ou de resistência, que cada comunidade produz de si mesma.

\section{Discursos sobre o aluno: o lugar social dos autores}

O estudo das revistas de educação e ensino permite-nos contemplar um espaço de produção discursiva característico daquele momento histórico. Os periódicos, de duração variada, constituíam um espaço de divulgação de saber que adquiria especial relevância ao longo dos oitocentos. No campo educacional, a necessidade de produção, circulação e apropriação dos saberes científicos que deveriam guiar o exercício do trabalho docente gestaram estratégias de formação e divulgação do conhecimento. Destaca-se a difusão de impressos educacionais, um dos dispositivos que conferiria uniformidade ao discurso pedagógico, elemento fundamental para a profissionalização do professorado (vide Nóvoa, 1987).

As revistas tinham forte consciência de seu papel histórico de divulgador do saber e de registro ${ }^{5}$, propiciador de uma memória do campo educacional. Através da produção e reprodução de textos científicos, fizeram circular um discurso normatizador e modelar, a ser absorvido pelo professorado, de forma a subsidiar sua prática e conferir-lhe capital cultural.

Porém, tais veículos não apresentavam uma identidade homogênea. Considerando a composição social diferenciada do público atendido pela 
escola, determinante de demandas educativas diversas, verifica-se a existência de múltiplos discursos, saberes e projetos de escolaridade. Tais discursos eram veiculados em distintos espaços de circulação do conhecimento, por autores inseridos em lugares sociais diversos, dotados de legitimidade também diferenciada. No dizer de Foucault (1997: 198),

há, de forma muito regular nas sociedades, uma espécie de desnivelamento dos discursos [...] embora os seus pontos de aplicação possam mudar, a função permanece; e o princípio de uma diferenciação encontra-se sem cessar reposto em jogo.

Nessa perspectiva, na análise das revistas, é fundamental considerar a especificidade de cada veículo, contemplando a identidade profissional dos autores dos textos, política editorial, concepção política-educativa, bem como a relação estabelecida com o público leitor, notadamente o professorado, de maneira a conferir visibilidade às "lutas das representações".

Buscando apreender a polifonia de discursos em torno do aluno da educação portuguesa, o resgate de diversas fontes e seu entrecruzamento foram recursos historiográficos fundamentais. Para tal, foram selecionados 6 três periódicos, entre a centena de revistas educacionais em circulação ao longo dos oitocentos. Recorreu-se também a fontes secundárias, analisadas em outros trabalhos de história da educação portuguesa voltadas para o período (vide Boto, 2003; Moreirinhas, 1990; Carneiro, 2003).

As fontes primárias contempladas foram os periódicos: $O$ Ensino, que circulou entre 1885 a 1890, a Revista de Educação e Ensino, que foi editada entre 1886 e 1900 e Educação Nacional, que foi publicada entre 1896 e $1976^{7}$.

O perfil de $O$ Ensino era definido nos seguintes termos:

[...] as transformações por que está passando atualmente o ensino popular no país inspiram-nos o desejo de empreender a publicação dessa revista que acompanhando a evolução iniciada fosse dando os leitores uma informação completa de todo este movimento das reformas, procurando ao mesmo tempo aquilatá-las em relação ao que por experiência sabemos da escola primária e por dignidade sentimos com respeito ao professor [...] tudo pelo ensino, tudo pelo professorado primário (Biblioteca Nacional [BN], O Ensino, 1885, n. 1, pp. $1-2)$.

Tendo experimentado significativa circulação à época, caracterizavase pela identificação com os docentes e suas reivindicações. O periódico 
divulgou sistematicamente questões relativas às condições de trabalho do professorado, contribuiu na promoção dos primeiros congressos profissionais, assumiu uma posição crítica em relação às diferentes reformas implementadas ao longo do período, principalmente a Reforma Jayme Moniz de $1895^{8}$. Ocupou, portanto, papel de destaque na conformação do movimento associativista docente, tão ativo no período estudado.

O caráter de identificação com o professorado expressava-se tanto na discussão de temas atinentes à dinâmica da sala de aula, como na divulgação de demandas profissionais. O periódico buscava assumir o papel de canal de expressão do grupo profissional, dimensão também expressa em seu programa editorial, em que anunciava a publicação de:

extratos dos atos oficiais, esclarecimentos e dados sobre frequência escolar, reclamações cujo assunto se relacione com o nosso periódico e se achem em termos que a comissão julgue convenientes, respostas sobre assuntos escolares contendo qualquer elucidação sobre disposições legislativas ou regulamentares (BN, O Ensino, 1885, n. 1, p. 2).

Sustentado em tal perfil, a revista publicava sugestões de estratégias de trabalho, divulgando as novas perspectivas metodólogicas, em que a linguagem e a abordagem definiam-se pela aproximação do professorado primário, difundindo um saber técnico relacionado ao ofício docente. Dimensão do periódico que tinha registro em seu editorial, em que propunhase a publicar: "questões teórico-práticas das escolas primárias, parte prática do ensino das diferentes matérias que constituem o programa das escolas, com destaque para a parte que se refere a pedagogia" (BN, O Ensino, 1885, n. 1, pp. 1-2).

Como comenta Boto (2003) acerca do discurso do professorado naquele período, este procurava mostrar-se presente no debate pedagógico erudito, tanto discutindo questões de ordem metodológica, quanto analisando os conteúdos a serem veiculados pela escola primária. O periódico Educação Nacional, que constitui exemplo de longevidade, começou a circular em 1896, tendo sido publicado até 1976. Definiu-se também, no período estudado, por um perfil identificado com o ensino primário e as demandas do professorado, assumindo posição crítica em relação às reformas implementadas e à política educacional do governo. A revista tinha um discurso de defesa da escolarização associando-a ao progresso do povo e da Nação, em que os 
artigos apresentavam forte conotação política, ao mesmo tempo que incorporavam termos do discurso científico, de forma a sustentar sua argumentação. Em um artigo da revista (BN, Educação Nacional, 1897, p. 337) se afirmava: "o progresso de uma nação está na razão inversa da difusão da luz pelas suas camadas sociais e na direta do quadrado do grau de ignorância em que vivem".

Tendo em vista um projeto político de transformação nacional, fundado no republicanismo, o ensino primário era considerado espaço fundamental de intervenção. No caso do discurso pedagógico português, observa-se a preocupação em apresentar os professores primários como obreiros da civilização (Boto, 2003).

Já a Revista de Educação e Ensino tinha outro perfil. Segundo Nóvoa (1993: 105): "a revista contemplava três núcleos temáticos: questões de natureza pedagógica e educativa, análise e crítica dos sistemas educativos e divulgação dos assuntos de natureza científica e cultural". Foi editada inicialmente por Ferreira Deusdado, médico e professor da Escola de Letras e, posteriormente, por Bethencourt Ferreira, também médico e higienista. Em seus editoriais, explicitava-se o papel difusor de saberes dotados de legitimidade, devido à posição social de destaque de seus autores, reconhecidos como representantes da intelectualidade lusitana. Eram basicamente especialistas inseridos em diferentes campos do conhecimento (médicos, educadores, juristas, políticos) e espaços institucionais, muitos destes diretamente envolvidos na produção e efetivação de políticas públicas educacionais.

A Revista expressava nos seguintes termos sua linha editorial e relação com o público leitor:

a Revista de Educação e Ensino deve pelo seu espírito condensar em forma acessível as recentes aquisições metodológicas, vulgarizando os preceitos científicos e pedagógicos e, desse modo, colocar-se a serviço da regeneração do nosso ensino público, sobretudo no nosso grau secundário, onde além do mais falta uma escola normal (BN, Revista de Educação e Ensino, 1889, p. 7).

O periódico estabelecia uma relação comparativa com outros impressos de divulgação do conhecimento, afirmando o caráter contemporâneo do veículo. Por um lado, contrapunha-se à enciclopédia, por entender que as revistas tinham uma identidade afinada com a especialização 
científica, característica do século XIX; por outro, ao livro, por apresentar-se como veículo dotado de maior dinamismo. Era a modernidade do impresso, identificado com as necessidades de atualização do conhecimento peculiares ao século XIX, que se pretendia proclamar:

... o engrossamento da corrente científica trouxe a necessidade do manual e da revista que é o fracionamento e a especialização oposta à enciclopédia de outros tempos [...] o jornal contempla e aperfeiçoa o livro. Este representa a ciência estática, isto é, num certo período, num certo momento, numa determinada ordem de ideias e fatos. O jornal ou revista periódica representa a ciência dinâmica, na materialidade dos seus processos e dos seus resultados, na multiplicidade de suas aplicações, na transformação evolutiva das ideias, que é a vida de uma ciência (BN, Revista de Educação e Ensino, 1895, p. 8).

O periódico não trazia marcas de interlocução com os professores (cartas, consultas, comentários sobre questões do cotidiano ou do associativismo docente) próprios dos outros veículos analisados. Verifica-se, na verdade, a presença de um discurso desqualificador do docente, representado como mal preparado para o exercício do ofício. Frente a isso, sua proposta era fazer circular os saberes científicos identificados com o universo acadêmico, numa posição distinta dos demais veículos que lhe eram contemporâneos.

A estrutura discursiva dos textos era fundada na apropriação das disciplinas acadêmicas que, como analisa Escolano (1999), mostravam-se desvinculadas das práticas e das diversas culturas nacionais, sendo postuladas como modelo de saber legítimo, a ser incorporado pelo professorado, de forma a guiar sua prática profissional.

A análise da Revista de Educação e Ensino indica, portanto, a crescente cientificização do campo pedagógico, em que a produção acadêmica era matriz de análise da problemática educacional. Foi no período estudado que construiu-se uma rede de dispositivos de afirmação e difusão dos saberes científicos que tanto se propunham a dar respostas às questões postas pela educação, quanto buscavam conferir aos especialistas, notadamente médicos, um espaço de exercício de poder e intervenção social. Como afirma Garnel (2003: 252), "ao longo do século XIX e início do século $\mathrm{XX}$, os médicos construíram um poder, tanto maior quanto mais conseguiram que sua voz fosse ouvida pelas instâncias do Estado e que as modificações dos comportamentos fossem interiorizadas pela população". 


\section{Discursos sobre o aluno: o professorado e a expressão de um saber técnico}

Tendo em vista o resgate dos discursos docentes, foi contemplada a análise da secção "Correspondências Recebidas", presente no periódico $O$ Ensino, coluna na qual os professores faziam consultas relativas ao exercício profissional. Foram contemplados também os mapas de matrícula e frequência enviados pelos professores ao periódico.

Busca-se investigar a expressão de um saber característico, entre o artesanal e o intelectual. Para Pintassilgo (1999: 89),

basta lermos a imprensa pedagógica ou as atas dos congressos pedagógicos para avaliarmos a forma como vão se afirmando, a esse nível, alguns princípios comuns [...] a produção de um discurso (em certa medida próprio) e bastante impregnado de preocupações deontológicas é, certamente, uma das aproximações possíveis entre a noção do intelectual e a figura do professor.

A revista desde seu primeiro número fez circular uma coluna contendo cartas com consultas dos professores primários sobre questões relacionadas ao desenvolvimento do seu ofício. Verifica-se a grande adesão por parte do professorado. O caráter dialógico de algumas das correspondências é indicativo da identificação com o periódico:

há muito que tenho a intenção de escrever [...] hoje que tenho um bocadinho de tempo, tomo-o para pedir sua opinião sobre um ponto que foi apresentado e discutido nas conferências pedagógicas de Argemil em 1881, esta questão era: qual a utilidade ou desvantagens das escolas mistas? (BN, O Ensino, 1882, p. 131).

$\mathrm{Na}$ resposta, recorre-se ao texto legal, aspecto que atravessa todas as manifestações da revista às consultas do professorado, em que o discurso jurídico buscava balizar e definir o campo pedagógico.

Observa-se uma centralidade da discussão acerca das questões associativistas, em que a imensa maioria das cartas voltava-se para consultas acerca de demandas salariais, férias, aposentadoria, aspectos relacionados à profissionalização docente. Destacam-se também as correspondências acerca das condições de trabalho, notadamente de moradia, já que os professores, em sua maioria, moravam em casas alugadas para funcionarem como salas de aula, sendo presentes as tensões na administração da superposição entre os domínios público e privado no cotidiano do professorado. 
O resgate do discurso dos docentes, fruto de sua experiência social indica a peculiaridade do saber profissional. Segundo Escolano (1999: 89), "na aprendizagem do ofício docente há predomínio dos modos de apropriação empírica das competências práticas que o coletivo dos professores foi configurando como regras artesanais de um trabalho especializado e semiprofissional".

No que se refere às questões atinentes à ordenação do trabalho pedagógico e à expressão dos saberes sobre o aluno, os professores em suas cartas centravam-se em alguns temas. Destaca-se a repetição de consultas sobre inserção e registro de alunos fora da faixa etária contemplada pelas leis de obrigatoriedade escolar, notadamente a recepção de alunos de mais de 12 anos. A preocupação dos professores referia-se não propriamente à administração no contexto escolar de alunos de idade diferenciada, mas ao registro dos mesmos e à viabilidade de recebimento do salário referente a frequência de tal público. Observa-se também a denúncia da recusa das juntas municipais de pagamento ao docente do aluno fora da faixa etária legal.

Das várias correspondências referentes a tal temática, apenas duas questionavam a recepção de alunos com idade inferior à prevista pela legislação, tendo a revista respondido que os professores não deveriam matricular tal público. Ao contrário, nas consultas sobre a inserção de alunos mais velhos, as respostas orientavam o professor a recebê-los, criticando as juntas municipais por fazer uma interpretação tão estrita do texto legal.

Relacionada a esta questão, apareciam consultas referentes a ordenação do trabalho com alunos situados em níveis diferentes de aprendizagem: "uma escola primária foi dividida em três classes para regularidade do serviço. Pergunta-se quais os alunos que formam a primeira classe? Os mais adiantados ou os mais atrasados?" A resposta do periódico deu-se nos seguintes termos: "Não havendo determinação legal nem convenção estabelecida que determina a adoção de um ou outro sistema, pode o professor seguir na escola aquele que tiver mais predileção" (BN, $O$ Ensino, 1885, p. 184).

A discussão acerca da escola graduada e da forma de geri-la aparece numa outra consulta:

numa escola funcionam simultaneamente as três classes em que se dividiu o curso de cada disciplina. Assim, na hora da leitura, todas as classes lêem, sob 


\begin{abstract}
direção do professor e monitores, na escrita todos escrevem, etc. Ora, como a aptidão de um mesmo aluno varia, muitas vezes segundo ele se aplica o estudo de um ou outra disciplina e como não seria justo retardar-Ihe o adiantamento unicamente para seguir paralelo com os de seu grupo ou classe a que até ali pertencera, visto que ao contrário não advém embaraço algum ao regular andamento da escola, uma vez adotada a simultaneidade do ensino de cada disciplina para toda a aula, terá a resultar frequentemente o ficar o mesmo aluno pertencendo a mais de uma classe, por exemplo, terceira em leitura, primeira em aritmética, etc. Nestas circunstâncias quando nos mapas estatísticos escolares houvermos de indicar, de um modo geral a que classe o aluno pertence como procederemos? Devemos indicar a média? Qual o processo para a obter? (BN, O Ensino, 1885, p. 253).
\end{abstract}

As consultas acerca da organização do trabalho pedagógico com alunos de diferentes níveis de aprendizagem indicam questões advindas de um modelo coletivo, em que o professorado deveria contemplar o nível de cada aluno, ao mesmo tempo que geri-lo no interior de um grupo. Tal problemática era significada pelos professores e pelo periódico, mediada por um saber técnico, relativo ao registro institucional, no que se define como uma forma própria de escrita: a escrituração escolar. A apropriação desta técnica escriturária, na manifestação do professorado, informava a análise de questões que delimitavam o campo pedagógico.

Destaca-se na análise da correspondência, bem como no registro das temáticas desenvolvidas nas conferências pedagógicas e nos programas de curso das Escolas Normais, a centralidade da escrituração escolar, entendida como corpus de conhecimento que permitiria o domínio de uma técnica relativo ao exercício da função.

Tal técnica revelava-se de fulcral importância na uniformização do funcionamento das salas de aula, na produção de dados que conferissem visibilidade, cientificamente sustentada, a um diagnóstico nacional da educação, bem como na gestão de um sistema ainda precário, possibilitando instrumentos de controle.

No caso das escolas, erigiu-se nesse período toda uma variedade de instrumentos técnicos de registro, acompanhamento, avaliação e controle das práticas desenvolvidas nas salas de aula, ou relacionados a instituição. Tais instrumentos constituíram um dos elementos da cultura escolar então em conformação, mediando a relação dos professores com o Estado, bem como configurando um aparato burocrático próprio. A revista reproduzia o seguinte texto sobre as tarefas escriturárias do docente: 


\begin{abstract}
Deveres do professor: os professores devem possuir registros anuais e semestrais para anotar a frequência e comportamento dos alunos, além de registros mensais, onde mais prontamente anotam sua frequência, segundo modelos elaborados, aprovados e fornecidos pela municipalidade, a fim de serem examinados pelas autoridades escolares municipais e governamentais. São igualmente obrigados a enviar aos pais dos alunos, desde que foi admitido na classe, um cartão impresso onde consta a sua admissão, convenientemente preenchido e assinado, cartão que os mesmos têm o cuidado de reclamar bimensalmente e no qual se registra o resultado do ensino durante este tempo (BN, O Ensino, 1888, p. 326).
\end{abstract}

A centralidade do domínio dos instrumentos de registro traduzia-se na transformação deste saber técnico em campo disciplinar, presente no currículo da Escolas Normais, nas disciplinas "Escrituração Mercantil" e "Redação de Assuntos Pedagógicos", nas quais se ensinava: "a redação de papéis oficiais a que é obrigado o professor primário" (apud Moreirinhas, 1990: 19), constituindo também tema das conferências pedagógicas. A importância do domínio desta escrita técnica tinha expressão na conclamação aos professores para que enviassem ao periódico o registro de seus mapas de frequência, elogiando os que respondiam a tal demanda, bem como publicando-os no periódico. Em comentários aos mapas enviados, a revista expressava seu júbilo: "o movimento desta importante escola expresso na clareza dos dados estatísticos que nos foram fornecidos" (BN, O Ensino, 1885 , p. 27), "os nossos colegas do magistério continuam a honrar-nos com os dados estatísticos de suas escolas" (BN, O Ensino, 1885, p. 148) ${ }^{9}$.

A escrituração escolar refere-se ao que Foucault denomina "escrita disciplinar", ou seja, uma rede de anotações escritas que captam e fixam o indivíduo, permitindo: "classificar, formar categorias, estabelecer médias, fixar normas" (1986: 169).

Tal escrita, fundada numa racionalidade técnica, exigiria a constituição cada vez mais minuciosa de dispositivos de controle, a atuarem não apenas a nível do Estado, mas a incidir sobre o indivíduo. Para o autor, o processo histórico de individualização dos sujeitos sociais, daria-se também através do registro minucioso e sistemático de sua ações, inscrevendo-os no interior de um conjunto.

Segundo Corbin (1991), conjuga-se, na produção sistemática de formas de registro do indivíduo ao longo do século XIX, a culminância do processo de individualização e a percepção de que o controle de cada sujeito era essencial à sobrevivência do grupo. 
Associa-se, no caso da escrituração escolar, o registro do comportamento singular de cada sujeito à sua inscrição num coletivo, que the conferia significação. Expressa-se, mais que uma técnica de registro, um dispositivo de governo, relacionado ao saber demográfico que se impôs como fator de governabilidade naquele período (Garnel, 2003).

O saber demográfico tinha na estatística a disciplina de sustentação, compreendida como instrumento de padronização social, disciplina que transformou-se em corpus de conhecimento capaz de conferir legitimidade à ciência pedagógica. Se o domínio dos seus pressupostos era fundamental para a estruturação do discurso dos especialistas, no caso dos professores, estes deveriam apropriar-se do saber técnico relacionado às formas de registro.

Cabe destacar, no entanto, que os periódicos também expressavam representações diferenciadas acerca da funcionalidade da estatística escolar. Enquanto $O$ Ensino mostrava-se vivo divulgador dos instrumentos padronizados de registro, A Educação Nacional pronunciava-se criticamente: "os professores trimestralmente remetem aos administradores do conselho uma lista com o número de crianças em idade escolar [...] pois tais listas vão dormir no cesto de papéis velhos e só servem para dar trabalho ao professor e mais nada" (BN, Educação Nacional, 1897, p. 314).

Quanto ao desempenho escolar dos alunos, as cartas mencionavam questões disciplinares em que os professores perguntavam como gerir as manifestações de indisciplina do alunado. Numa consulta, o professor questionava, diante do comportamento do aluno, indicativo de sua expulsão, quem seria responsabilizado pelo pagamento da multa pelo não cumprimento da lei da obrigatoriedade escolar: os pais do aluno faltoso ou o professor que decidiu por sua exclusão. Mesmo considerando que a lei foi pouco aplicada ao longo do período, os termos da consulta indicam uma relação com o Estado pautada pelo rígido controle do desempenho do seu ofício. Controle que aparece noutra correspondência: "não havendo na povoação em que funciona a escola, relógio público, o professor tem de regular a entrada e saída pelo seu ou pelo dos particulares [...] e quando o seu não regula pelos dos outros, tem que sofrer alguma pena disciplinar?" (BN, O Ensino, 1878, p. 34).

O trabalho do professorado achava-se submetido ao controle das Juntas Municipais e principalmente dos inspetores de ensino. Em discurso de 
posse desses profissionais, Carneiro (2003: 45) registra o seguinte discurso de um inspetor, relativo ao caráter de sua função: "...quando os professores, pela sua negligência e desleixo, faltarem ao cumprimento de suas obrigações, depois de devidamente prevenidos e aconselhados, V. Senhoria promoverá sem hesitação nem condescendência a aplicação das penalidades estabelecidas pela lei".

Boto (2003) também apresenta o seguinte comentário de um docente, sobre o controle a que era exposto o professorado:

e hoje impõem graves castigos aos professores por qualquer falta cometida no exercício de suas funções, temos, contudo, direito a que nos dêem a consideração devida ao sacerdócio que exercemos [...] esperamos, pois que em breve, soará a hora da emancipação do professorado primário! [...] unamonos pois, colegas, que a vitória será nossa (Guerreiro, 1898).

O resgate das manifestações do professorado demonstra que havia arraigado sentimento de pertencimento a uma categoria profissional, com demandas específicas, que era organizado de forma a contrapor-se as sanções por parte do Estado, ao mesmo tempo que apropriava-se da imagem do sacerdócio, tomado como expressão característica do ofício. Ofíco definido pelo manejo de um saber técnico, o qual mediava a interpretação de questões referentes ao cotidiano escolar. Estas questões tinham por parte dos especialistas uma interpretação diversa, sustentada na ciência pedagógica, o que será analisado a seguir.

\section{Discursos sobre o aluno: os especialistas}

Como contraponto à expressão de saberes do professorado, foi fundamental a análise dos discursos dos especialistas que, nesse período histórico, assumiram o lugar de detentores do conhecimento pedagógico, influindo diretamente na formulação de políticas educacionais, bem como na constituição e difusão de uma cultura escolar identificada com a modernidade pedagógica, fazendo circular discursos dotados de maior legitimidade social.

Na tensão entre tais discursos ocorre o que Escolano (1999: 25) define como "la interdependência entre la desvaluacion de la profission docente y de los profesores como produtores de conocimiento, asi como la correspondente aparicion de nuevos grupos de expertos que se afirman como autoridade cientifica en el cargo de la educacion". 
Se os distintos discursos repercutiam o lugar social de seus autores, revelam também a diferenciação de sua estrutura textual, bem como de seus espaços de circulação. A Revista de Educação e Ensino entendia seu papel difusor como regenerador do ensino, exercido através da circulação de saberes científicos, numa posição distinta dos demais veículos que lhe eram contemporâneos.

Cabe considerar os autores e possíveis leitores da revista, publicada em Lisboa, num período de conformação de uma "burguesia esclarecida" (Proença, 1997) na capital e com demandas diferenciadas em relação à escola do restante do país. Verifica-se na análise da estrutura discursiva dos textos que tinha-se como leitor modelo um sujeito com um nível de letramento capaz de compreender o vocabulário, as referências e a organização do texto científico, ou seja o professor do ensino liceal. Por outro, os temas tratados relacionavam-se a questões escolares próprias dos extratos médios urbanos da população, discutindo fenômenos como fadiga escolar (fadiga não relacionada ao exercício do trabalho), apatia, miopia, etc., a pertinência do ensino do alemão nas escolas, temas pouco afeitos a escolas primárias do interior do país, com problemáticas bastante distintas das contempladas pelo periódico. A centralidade da educação secundária era expressa nos artigos:

eis-nos chegado ao único grau de ensino que o nosso país consegue prender a atenção pública e até por vezes, apaixoná-la: Não que entre nós não se editem, com larga lógica de conhecimento, os árduos problemas em que o ensino primário se enreda; mas porque é a instrução burguesa, a instrução de todos e que todos querem simplificada [...] reina no assunto plena paz e concórdia entre os portugueses: todos querem um curso em poucos anos e com programas simples (BN, Revista de Educação e Ensino, 1889, p. 215).

As temáticas tratadas pelo professorado eram também trabalhadas nos artigos dos especialistas, tendo aí uma expressão diferenciada, fundada no cientificismo característico do período. Ao contemplar a diversidade geracional da composição do corpo discente, os periódicos lançavam mão de discursos referidos à psicogenia nascente, analisando as diferenças das competências de aprendizagem de alunos de idades variadas.

Os discursos sobre o aluno ocupavam grande parte da produção da Revista de Educação e Ensino. A revista dialogava com a produção acadêmica mais recente, revelando, ao longo de sua existência, um progressivo deslocamento de um referencial estritamente positivista, para o 
de divulgação da antropometria emergente, na análise dos processos de desenvolvimento humano. Tal saber deveria sustentar a apreensão das crescentes capacidades de aprendizagem do aluno.

Nos artigos do periódico, o estudo do desenvolvimento humano era sustentado inicialmente na chamada hipótese da recapitulação de Haeckel ${ }^{10}$, autor frequentemente citado: "a série de formas pelas quais passa 0 organismo individual, desde a célula primitiva, até o desenvolvimento pleno, é tão somente a repetição em miniatura da longa série de transformações pelas quais passavam os antepassados do mesmo organismo desde os tempos mais remotos até os nossos dias" (BN, Revista de Educação e Ensino, 1887, p. 78). Os professores deveriam, na compreensão dos processos de desenvolvimento do aluno, recorrer ao estudo da evolução da espécie. Para tal, o conhecimento da história humana, ou mais exatamente da história da civilização (e não das civilizações), constituía a referência central.

Ao fundamentar a análise dos processos de evolução histórica da humanidade, a revista reproduzia a teoria dos três estágios postulada por Comte, base para apreensão dos processos de desenvolvimento individual. Mais do que o positivismo, ou uma interpretação spenceriana do evolucionismo ${ }^{11}$, o cientificismo constituía a marca maior da produção do periódico, a crença no poder da ciência na regeneração social portuguesa, através de uma educação nacional fundada nos pressuspostos epistemológicos da época. No dizer de Catroga (1998:106),

a ação tinha de ter (de transformação da sociedade portuguesa) uma índole cultural e, por consequência, a educação das elites aparecia-lhe como uma tarefa inadiável [...] a realização de tal desiderato passava pela concretização de um plano educativo inspirado, em última análise, no espírito positivo e na ordenação sistematizada de saberes. Só assim a cultura poderia vencer a natureza e a evolução poderia objetivar-se como verdadeiro progresso.

Observa-se paulatinamente um deslocamento nos referenciais que sustentavam a apresentação da ciência psicogenética. Verifica-se o que Catroga (op. cit.) define como: "a defesa da redução da realidade psíquica à realidade fisiológica". Dimensão que se fez presente também no periódico Educação Nacional, ao comentar a necessidade do professorado adquirir o livro: "Bosquejos de anatomia e fisiologia", apresentado como fundamental para a "aquisição de conhecimentos que sustentariam a compreensão dos processos de desenvolvimento do indivíduo". 
Tal deslocamento reflete a posição de destaque cada vez maior do saber médico na definição da ciência da educação. Para Ferreira (2002: 103), "era preciso determinar as condições de desenvolvimento da criança e isto era função reservada à medicina [...] possuindo um discurso sobre o desenvolvimento da criança adequado ‘a concepção científica da época, a medicina alarga o seu campo de ação e seu poder de intervenção".

De uma leitura fundada na biologia e numa perspectiva historicista comtiana, passa a assumir centralidade a veiculação de preceitos médicohigienistas, no diálogo com a antropometria emergente, alterando-se a percepção e análise dos processos de desenvolvimento humano e de organização do campo pedagógico. Com o avanço dos estudos fisiológicos, foi-se delineando uma perspectiva diferenciada, de cunho empiricista, voltada para a construção de estratégias de investigação centradas no estudo da criança concreta, através da mensuração dos seus caracteres anátomofisiológicos, definidos por seu pertencimento sócio-racial.

De acordo com o periódico, o tipo e quantidade de trabalho a ser desenvolvido com crianças teria como categorias balizadoras a idade e a raça: "a experiência dos pedagogistas corroborada pela prática dos mestres chega as seguintes conclusões quanto a capacidade de trabalho mental das crianças na escola: para cada idade como para as diferentes raças há uma capacidade diversa de trabalho. Tudo que exceda esse limite de capacidade é prejudicial" (BN, Revista de Educação e Ensino, 1990, p. 41).

Operação esta que reflete a centralidade da relação raça/história na produção do conhecimento do século XIX, em que tais eixos constituíram elementos catalizadores na apreensão dos mais distintos fenômenos. Verifica-se, portanto, a mudança paulatina nos paradigmas de análise dos processos de desenvolvimento humano: de um olhar historicista, de base positivista, para uma perspectiva fundada na análise das diferenças raciais, o que fez deslocar a força do ideário comtiano, embora este mantivesse sua marca na postulação de uma ciência objetiva.

Já nas demais revistas a discussão sobre os processos de desenvolvimento do aluno tinha em vista, não tanto a divulgação dos saberes acadêmico-científicos, mas a difusão das novas metodologias pedagógicas, fundadas em tais postulados. Buscava-se irradiar para um público leitor de professores do ensino primário o modelo de escola graduada, contraposto à 
escola fundada na memorização de conhecimentos, compreendida como pouco científica.

Eram frequentes as referências a um saber sustentado na psicologia sobre a importância de considerar o processo evolutivo do aluno, na ordenação dos conteúdos escolares, em nome do desenvolvimento de uma escola moderna:

na escola moderna cumpre acabar de vez com o atrofiamento do desenvolvimento normal das faculdades infantis, graduando o ensino pela força sempre crescente das mesmas faculdades, a mudar completamente o método e os processos de ensino [...] desenvolvendo normalmente as faculdades da criança, segundo passo a passo a lei da evolução mental (BN, O Ensino, 1885, p. 32).

Noutro trecho, o autor é enfático na defesa do conhecimento das fases da evolução mental: "é indispensável o estudo e conhecimento das leis segundo as quais tem lugar o desenvolvimento progressivo do ser humano, as manifestações dos seus instintos" (BN, O Ensino, 1887, p. 141).

Observa-se, portanto, nos artigos dos especialistas, por um lado, uma arraigada concepção cientificista, por outro lado, diferenciavam-se, de acordo com o veículo difusor e o público a quem era dirigido, os discursos e as estruturas textuais.

\section{Conclusão}

A análise das produções discursivas, em circulação na educação portuguesa do período, indica uma concepção de ciência própria daquele momento histórico. Como afirma Foucault (1997: 15), "há sem dúvida, uma vontade de verdade no século XIX que, nem pelas formas que põe em jogo, nem pelos domínios de objetos aos quais se dirige, nem mesmo pelas técnicas sobre as quais se apoia, não coincide com a vontade de saber que caracteriza a cultura clássica".

O forte cientificismo era resultante não apenas do inequívoco desenvolvimento técnico-científico, mas também das relações de poder/saber característicos daquele momento histórico. Os chamados especialistas, mais destacadamente os médicos, conseguiram afirmar-se socialmente como grupo profissional capaz de responder, na posse de um conhecimento especializado, às novas demandas sociais, no caso em análise, a uma cientificização do campo pedagógico. 
Nesse ordenamento, os professores viram-se projetados como depositários de discursos, detentores de um conhecimento dotado de menor legitimidade social. Nesta trama, seria através do aprendizado deste saber científico que o professorado poderia afirmar-se como grupo profissional reconhecido.

Cabe destacar que o professorado não constituía um grupo uniforme, nem em suas práticas nem na relação com o saber científico. Os professores secundários, destinatários privilegiados dos discursos acadêmicos do periódico Revista de Educação e Ensino eram representados como grupo cujas características o aproximavam do perfil intelectual. Já os professores primários, destinatários dos discursos das demais revistas analisadas, discursos estes voltados para o manejo do cotidiano escolar, afirmaram-se historicamente como grupo social diferenciado, cujo ofício era definido por uma prática artesanal, técnica e semi-especializada.

Verifica-se que os discursos não apenas tinham em vista leitores diferenciados, mas que estes eram produzidos pela estrutura e conteúdo dos textos, bem como pela identidade dos espaços de difusão. Como indica Eco (1983), no processo de construção textual, o autor não apenas supõe um leitor modelo, dotado de determinadas competências linguísticas que tornem possíveis a leitura, mas projeta tais competências no ato da escrita. No caso em análise, afirma-se no período uma identidade profissional distinta entre os docentes de acordo com seu nível de atuação, distinção para a qual a diferenciação das produções discursivas presentes nos periódicos teve papel fundamental.

Por outro lado, se os médicos constituíram o grupo profissional privilegiado na produção e difusão do ideário pedagógico ao longo do período analisado, tal relação alterou-se na primeira metade do século XX. Neste momento, os saberes sobre o aluno tornaram-se domínio de um novo grupo profissional: os psicólogos, detentores do conhecimento sobre a criança, definitivamente proclamada como centro da ação pedagógica. A psicogenia nascente do final dos oitocentos, sustentada em outros campos disciplinares como a biologia, a história e a fisiologia, afirmou-se na nova centúria como corpo científico distinto, com identidade própria, fundada em instrumentos de investigação e medida singulares, o que reconfigurou também a concepção de especialista da educação. Mas esta é já uma outra história. 


\section{Notas}

1 Pesquisa desenvolvida no decorrer do pós-doutoramento na Universidade de Lisboa. Agradeço a Rogério Fernandes a competente orientação e a Margarida Felgueiras, Antonio Ferreira, Manuel Sarmento, Justino Magalhães, Isabel Madeira, Jorge do Ó as preciosas interlocuções.

2 Vide, entre outros, Fernandes \& Magalhães (1999); Proença (1997); Barroso (1995); do Ó (2003); Nóvoa (1986; 1987); Fernandes (1979); Candeias (2004); Cardona (1997); Carvalho (1994).

3 Segundo dados publicados em Educação Nacional (1897: 32): "no exercício de 1896/1897 foram destinados ao ensino primário 218971727, de um total de 1171505258".

4 Cabe, contudo, destacar o instigante trabalho de do Ó (2003).

5 É interessante fazer notar que o periódico Revista de Educação e Ensino possuía uma seção - História da Educação - na qual publicava registros históricos de instituições educacionais portuguesas (por ex., Universidade de Coimbra), compreendendo-se como depositária e divulgadora da memória educacional lusa.

6 A seleção contemplou a circulação, prestígio social dos autores e editores da publicação, aspectos analisados a partir do repertório analítico sobre a imprensa educacional portuguesa (vide António Nóvoa, 1993).

7 Na análise, contemplei apenas os números que circularam entre 1896 e 1900.

8 A Reforma Jayme Moniz, voltada para o reordenamento do ensino secundário, teve profundo impacto nos meios educacionais e políticos portugueses, gerando reações diversas (vide Proença, 1997 e Fernandes \& Magalhães, 1999).

9 É interessante fazer notar a forma propositadamente horizontalizada de referir-se aos docentes, "colegas de magistério", demonstrativo do caráter de identificação do periódico com o professorado.

10 Para melhor compreensão da hipótese da recapitulação e seu papel na educação do período, vide Gouvea (2008).

11 A citação aos princípios evolucionistas, na interpretação de Spencer, eram também constantes no periódico.

\section{Referências}

BARROSO, João (1995). Os Liceus: Organização Pedagógica e Administração (18361960). Lisboa: Fundação Calouste Gulbenkian.

BOTO, Carlota (2003). O professor primário português como intelectual: eu ensino, logo existo. Revista História das Ideias. Vol. 24, pp. 87- 101.

CANDEIAS, António, Org. (2004). Alfabetização e Escola em Portugal nos Séculos XIX e XX. Lisboa: Fundação Calouste Gulbenkian.

CARDONA, Maria João (1997). Para a História da Educação da Infância em Portugal. O Discurso Oficial (1834-1990). Porto: Ed. do Porto. 
CARNEIRO, António H. (2003). A Inspecção do Ensino em Portugal: nos Finais do Século XIX e Alvores do Século XX. Lisboa: Fundação Calouste Gulbenkian.

CARVALHO, Rómulo (1994). História do Ensino em Portugal. Lisboa: Fundação Calouste Gulbenkian.

CHARTIER, Roger (1991). A História Cultural. Lisboa: Difel.

CATROGA, Fernando (1998). Positivistas e republicanos. In J. L. Torgal; J. A. Mendes; F. Catroga (Orgs.), História da História em Portugal. Sécs. XIX-XX. Coimbra: Temas e Debates, pp. 94 - 121.

CORBIN, Alain (1991). O segredo do indivíduo. In M. Perrot (Org.), História da Vida Privada, n. 4. São Paulo: Companhia das Letras, pp. 419- 502.

ECO, Umberto (1983). Lector in Fabula. São Paulo: Perspectiva.

ESCOLANO, Agustin (1999). Los profesores en la historia. In J. Magalhães \& A. Escolano (Orgs.), Os Professores na História. Porto: Sociedade Portuguesa de História da Educação, pp. 73-98.

FALCON, Francisco (1997). História das ideias. In C. Cardoso \& R. Vainfas (Orgs.), Domínios da História. Rio de Janeiro: Campus, pp. 91- 126.

FALCON, Francisco (2003). Introdução à História Moderna. In A. Marques; F. Berutti \& R. Faria (Orgs.), História Moderna através de Textos. São Paulo: Contexto, pp. 11-14.

FERNANDES, Rogério (1979). A Pedagogia Portuguesa Contemporânea. Lisboa: Instituto de Cultura Portuguesa.

FERNANDES, Rogério (1998). Génese e consolidação do sistema educativo nacional (1820-1910). In M. C. Proença, O Sistema de Ensino em Portugal. Lisboa: Instituto de História Contemporânea/Universidade Nova de Lisboa, pp. 48 - 63.

FERNANDES, Rogério \& MAGALHÃES, Justino, Orgs. (1999). Para a História do Ensino Liceal em Portugal. Braga: Universidade do Minho.

FERREIRA, António Gomes (2002). Higiene e o investimento médico na educação da infância. In J. Gondra (Org.), História, Infância e Escolarização. Rio de Janeiro: 7 Letras, pp. 96-109.

FOUCAULT, Michel (1987). A Ordem do Discurso. Lisboa: Relógio d’Água.

FOUCAULT, Michel (1986). Vigiar e Punir. Petrópolis: Vozes.

GARNEL, Maria Rita (2003). O poder intelectual dos médicos: final do século XIX- início do século XX. Revista de História das Ideias, n. 24, pp. 213-235.

GOUVEA, Maria Cristina (2008). Estudos sobre desenvolvimento humano no século XIX: da biologia à psicogenia. Cadernos de Pesquisa, v.39, n.134, pp. 535-557.

GUERREIRO, Custódio (1898). Aspirações e Protestos do Professorado Primário: Memórias e Pareceres Apresentados nos Congressos Pedagógicos de Lisboa e Porto. Lisboa: Typographia Nacional.

MOREIRINHAS, J. Eduardo P. (1990). A Escola Normal de Lisboa. Lisboa: Tipografia Nacional.

NÓVOA, António (1986). Do Mestre-escola ao Professor do Ensino Primário: Subsídios para a História da Profissão Docente em Portugal (Sécs. XVI-XX). Lisboa: Universidade Técnica. 
NÓVOA, António (1987). Les Temps des Professeurs: Analyse Socio-historique de la Profession Enseignante au Portugal, I vol. Lisboa: Instituto Nacional de Investigação Científica.

NÓVOA, António (1988). A história do ensino primário em Portugal. In R. Fernandes (Org.), I Encontro de História da Educação em Portugal. Lisboa: Fundação Calouste Gulbenkian, pp. 23-29.

NÓVOA, António (1993). A Imprensa de Educação e de Ensino - Repertório Analítico (Séculos XIX e XX). Lisboa: Instituto de Inovação Educacional.

Ó, Jorge do (2003). O Governo de Si Mesmo. Lisboa: Educa.

PINTASSILGO, Joaquim (1999). O mestre como artesão/prático e como intelectual. In J. Magalhães \& A. Escolano (Orgs.), Os Professores na História. Porto: Sociedade Portuguesa de Ciências da Educação, pp. 72-91.

PROENÇA, Maria Cândida (1997). A Reforma Jayme Moniz. Lisboa, Colibri.

\section{DISCOURSES, KNOWLEDGE AND POWER: A STUDY OF TEACHERS' AND EXPERTS' WRITINGS IN PORTUGUESE EDUCATIONAL JOURNALS}

\section{Abstract}

The paper analyses teachers' and experts' discourses about students in Portuguese educational periodicals of the last decades of the XIXth century. In this sense, it focuses the singularity from the discourses related to the professional identity of the authors. Its possible to identify that the experts writings were founded on a scientificist perspective, which characterized that historical period. On the other hand, the teachers discourses were the expression of a technical knowledge, related to their professional writing practices. Its possible to observe a social hierarchical relationship between the two discourse productions, associated with the relationships between knowledge and power.

Keywords

Teachers; Experts; Discourses; Educational Journals 
DISCOURS, SAVOIRS ET POUVOIR: UNE ÉTUDE DES ÉCRITS DES PROFESSEURS ET DES SPÉCIALISTES DANS LES REVUES EDUCATIONNELLES PORTUGAISES

Resumen

El texto analiza los discursos producidos sobre el alumno por los maestros y expertos en los periódicos de educación portugueses del final de lo siglo XIX. Así es que es posible percibir la singularidad de los discursos, relacionados con la identidad profesional de los autores. Los escritos de los expertos eran fundados en una perspectiva cientificista que caracterizaba esto periodo. Por otro, los discursos de los maestros expresaban un conocimiento técnico asociado a sus prácticas de escritura profesional. Por tanto, si observa una relación jerárquica entre las dos producciones en que saber era asociado a poder.

Palabras clave

Maestros; Expertos; Discursos; Periódicos de educación

Recebido em Abril, 2007 Aceite para publicação em Setembro, 2008

Toda a correspondência relativa a este artigo deve ser enviada para: Maria Cristina Soares de Gouvêa, Rua Grão pará 981 apto. 903, São Lucas, Belo Horizonte, CEP: 30150341, Minas Gerais, Brasil. 